\title{
Epidemiological and Occupational Profile of Anesthesiologists Practicing in Belo Horizonte, Minas Gerais - Brazil, in 2010
}

\author{
Bárbara Silva Neves ${ }^{1}$, Tarcísio Márcio Magalhães Pinheiro ${ }^{2}$
}

Summary: Neves BS, Pinheiro TMM - Epidemiological and Occupational Profile of Anesthesiologists Practicing in Belo Horizonte, Minas Gerais - Brazil, in 2010.

Background and objectives: Exposed to many occupational risk factors, the anesthesiologist should know how to experience situations related to work and everyday life, so that illness is not part of his reality. Knowledge of work through the worker himself is one way to look deeper into the universe surrounding health professionals in order to seek effective solutions that increase satisfaction and minimize damage. The objective of this paper was to outline an epidemiological and occupational profile of the anesthesiologist in Belo Horizonte, Minas Gerais.

Methods: Quantitative, cross-sectional randomized study conducted among members of the Society of Anesthesiology of Minas Gerais. Data collected through a questionnaire, including the CAGE, for evaluation of alcoholism and Self-Report Questionnaire (SRQ-20) to evaluate the prevalence of common mental disorders (CMD).

Results: There was predominance of male (62.4\%) working on-call schedule (91.1\%), both day and at night. The average number of night shifts was $5.4 \%$ in the last 30 days. Most of them $(88.3 \%)$ working in emergency departments. Most professionals reported being very tired and overloaded or very overloaded, but satisfied with the work. There was statistical association between CAGE positive and work overload and between CAGE and SRQ-20.

Conclusions: The population studied indicates that the anesthesiologist is a professional rather overloaded, which corroborates trends seen in the medical field. Major attention should be given to these professionals who live surrounded by harmful occupational hazards.

Keywords: Anesthesiology; Quality of Health Care; Safety; Occupational exposure; Health Personnel.

\section{INTRODUCTION}

The relationship between human beings and work is very restrict, and it is surrounded by elements other than damages 1,2 .

In the search for a plane understanding, the worker and his work (one giving meaning to the other) should be done in a comprehensive manner, as the knowledge of this relationship leads to the elucidation of the health/disease process attuned with the set of values, beliefs, ideas, and workers' social representations. In this context, the concepts advocated by occupational health are marked by offering a broad view that recognizes the various areas surrounding the professional's life and breaks with the conception of injury and agent, or specific group of agents, as a single causal link in the process of

Received from Public Health Department; Universidade Federal de Minas Gerais, Brazil.

1. Anesthesiologist, Santa Casa de Belo Horizonte; MSc in Public Health/Occupational Health, Universidade Federal de Minas Gerais (UFMG).

2. Professor, Department of Preventive and Social Medicine, UFMG; PhD in Public Health, Universidade de Campinas (Unicamp).

Submitted on October 24, 2011.

Approved on December 4, 2011.

Correspondence to:

Bárbara Silva Neves, MD

Rua Herval, 423/401 - Serra

30240-010 - Belo Horizonte, MG, Brazil

E-mail: nevesbs@bol.com.br illness. Subjectivity is also of concern because the worker's participation becomes part of the understanding and design of the work process ${ }^{3}$. Thus, the representation of a universe is the first step in the quest for understanding, followed by the search for the meaning given by the worker to his work, which breaks with the assumption to elucidate the true thought of the worker in the health-work-disease process. These features will be sought in the present study with the group of anesthesiologists practicing during the year 2010 in the city of Belo Horizonte, Minas Gerais.

\section{METHODS}

In this study, the use of quantitative techniques of data collection proved to be convenient to characterize the sample and undertake a comprehensive descriptive analysis of a group of workers. This methodology has sought to promote the involvement of the subject and from that represent the universe of those who experience the daily practice of anesthesiology. For data collection, a questionnaire was prepared with questions about the health professional identification including training, description of the work process and its conditions; relation to work and perception of the working universe, which gives meaning to the work-risk-health-illness relationship. Previously validated questionnaires were also used, such as the Cut down/Annoyed/Guilty/Eye-opener (CAGE) ${ }^{5}$ and Self-Report 
Questionnaire-20 (SRQ-20) 6,7. In this case, seven positive responses were considered indicative of common mental disorders $(\mathrm{CMD})^{8,9,10}$.

A randomly selected group undertook a test prior to the survey to characterize the feasibility of the questionnaire.

Data collection was conducted in the city of Belo Horizonte with the support of the Society of Anesthesiology of Minas Gerais (SAMG) and was based on the address registered as the city of Belo Horizonte. In total, 367 members were included for randomization, with 326 active professionals and 41 assistants. Taken into consideration that this study is exploratory, with an error of $5 \%$ and a significance level of $10 \%$, the size of the representative cohort sample was of 157 anesthesiologists ${ }^{11}$. The survey was approved by the Ethics Research Committee of the Universidade Federal de Minas Gerais (COEP-ETIC 0344.0.203.000-10). Data were tabulated in a database and statistically analyzed using the statistical software SPSS 17.0 (Statistical Package for Social Science). To assess the existence of an association between CAGE and SRQ-20 and work overload, chi-square test was used ${ }^{11}$.

\section{RESULTS}

We applied 157 questionnaires between October 1, 2010 and December 28, 2010. For many reasons, 36 anesthesiologists were replaced in the study, according to the criteria proposed for exclusion and inclusion. The results regarding sex, age, and marital status of participants is shown in Table I.

Table I - Distribution of Anesthesiologists from Belo Horizonte According to Age, Sex, and Marital Status, year 2010

\begin{tabular}{lll}
\hline Category & Frequency & $\%$ \\
\hline Sex & 59 & \\
Female & 98 & 37.6 \\
Male & 157 & 62.4 \\
Total & & 100.0 \\
Age Group & 2 & \\
$<30$ years & 59 & 1.3 \\
$30-39$ years & 55 & 37.6 \\
$40-49$ years & 26 & 35.0 \\
$50-59$ years & 15 & 16.6 \\
$60-69$ years & 157 & 9.6 \\
Total & & 100.0 \\
Marital Status & 115 & \\
Married & 8 & 73.2 \\
Divorced & 26 & 5.1 \\
Single & 7 & 16.1 \\
Other & 1 & 4.5 \\
Not Informed & 157 & 0.6 \\
Total & & 100.0 \\
\hline
\end{tabular}

The distribution for higher level of education showed the Specialist in Anesthesiology (TEA) as a major title for 70 of the respondents (44.6\%), followed by the Anesthesiology Superior Title (TSA from Portuguese) for 34 (21.7\%); residency in anesthesiology for $31(19.7 \%)$, complete or in progress master's degree for $12(7.6 \%)$, and complete or in progress doctoral or postdoctoral for $9(5.7 \%)$. The time practice of anesthesiology was one year (minimum) and 44 years (maximum), mean of 16.1 years.

Table II shows the percentage of weekly time devoted to anesthesiology and related activities, but two participants did not answer this question. Regarding the activity as an anesthesiologist, the work schedule of night shift is practiced by $91.1 \%$ of participants and only $7.6 \%$ do not work in this scheme. Considering only those who answered the question, the percentage rises to $92.26 \%$ (143) working in night shift and $7.74 \%$ who do not work in this scheme.

As for time shifts, of the 143 physicians, $79.7 \%$ work in day and night shifts, $10.5 \%$ in day shifts, and $9.8 \%$ in night shifts. Considering the distribution by quartiles, $25 \%$ of respondents worked between none and two night shifts in the last 30 days, $50 \%$ between two and four shifts, and $25 \%$ more than four night shifts in the last 30 days. Of 139 respondents, $7.91 \%$ do not work in shifts in areas of urgent and emergency care.

Regarding the workplace, 67 anesthesiologists devote $100 \%$ of their working time to hospitals. Considering all respondents, the mean weekly time devoted to the hospital is $88.6 \%, 12.5 \%$ to clinics, $9.9 \%$, to the office, and $9.8 \%$ to other places.

Regarding the type of health insurance used by patients (three did not respond), the mean is $57.1 \%$ health plan, $44.3 \%$ SUS (Brazilian Unified Health System), 9.5\% individuals, and $6 \%$ other types.

Data on anesthesia applied to patients according to their physical status were on average 33.7\% ASA I, 43.3\% ASA II, $17.8 \%$ ASA III, 7.1\%, ASA IV, 3.1\% ASA V, and 2.6\% ASA VI. Regarding surgery complexity (two participants did not respond), there were low $(36.9 \%)$, medium $(40.6 \%)$, and high $(24.9 \%)$ complexity.

There was job overlapping, as one single anesthesiologist has one or more jobs. Thus, $65.6 \%$ reported being self-employed, $63.1 \%$ were partners in anesthesiologist companies, $47.1 \%$ employees, $16.6 \%$ hired by some service, and $0.6 \%$ reported having another source of work.

Regarding work conditions and considering 155 respondents, the office received the highest rating followed by the hospital. Time interval for meals was also investigated and showed a mean of 31 minutes, with a minimum of zero (no interval for meals) and maximum of 90 minutes. Considering the division by quartiles, $25 \%$ of respondents have between zero and 20 minutes for meals and only $25 \%$ have longer than 40 minutes. Intervals for meals were considered inadequate by 101 of anesthesiologists (64.3\%), sufficient by $45(28.75 \%)$, and $9(5.75 \%)$ reported having no time interval for meals.

The mean time to rest at work was 15 minutes, with maximum of 360 minutes and minimum of zero. Excluding two reported values of 360 minutes, the mean drops to 10 . Among 151 respondents, time to rest is nonexistent for $68.2 \%$ and $14.1 \%$ reported 20 minutes or less. 
Table II - Weekly Time Dedicated to Anesthesiology and Related Activities by Anesthesiologists from Belo Horizonte, year 2010

\begin{tabular}{|c|c|c|c|c|c|c|c|}
\hline \multirow[b]{2}{*}{ Activity } & \multicolumn{5}{|c|}{ Weekly Time Dedicated to Each Activity } & \multicolumn{2}{|l|}{$\mathrm{Cl}(95 \%)$} \\
\hline & N\# respondents & Min & Max & Mean & SD & Lower limit & Upper limit \\
\hline Anestesiology & 155 & $50.0 \%$ & $100.0 \%$ & $93.2 \%$ & $12.5 \%$ & $91.2 \%$ & $95.2 \%$ \\
\hline Intensive Care & 9 & $5.0 \%$ & $20.0 \%$ & $11.1 \%$ & $7.0 \%$ & $5.8 \%$ & $16.5 \%$ \\
\hline Pain Clinic & 12 & $1.0 \%$ & $35.0 \%$ & $12.7 \%$ & $11.2 \%$ & $5.6 \%$ & $19.7 \%$ \\
\hline Other Proffessional Activity & 38 & $2.0 \%$ & $50.0 \%$ & $21.2 \%$ & $14.8 \%$ & $16.3 \%$ & $26.0 \%$ \\
\hline
\end{tabular}

When asked about their relations to work, $94.9 \%$ of anesthesiologists reported some level of overhead and 96.8 some level of tiredness. However, regarding job satisfaction, $95.5 \%$ reported some level of satisfaction, while $77.1 \%$ would not have chosen another profession or medical specialty.

With respect to tasks performed, $52.2 \%$ said that tasks vary with days of the week and $37.6 \%$ said that work activities are always the same or vary slightly.

Current health status was considered good by $45.9 \%$ of respondents and $24.2 \%$ consider it very good. Only $1.3 \%$ considers it bad, and none of them considers their health as very bad. More than half of respondents $(52.9 \%)$ have some kind of health problem. They reported 35 different health problems present in 95 subjects, with 22 of them complained of two or more health problems. The health problem most often reported by 14 individuals was Hypertension (HBP), followed by stress and herniated discs, mentioned seven times each. Use of any medication on regular basis was reported by $48.4 \%$ (79) of participants, with 39 different medications mentioned, the most used (16 individuals) belong to the class of anxiolytics, followed by antidepressants (seven individuals) and omeprazole and statin (five subjects each). The relationship between health and work is shown in Table III.

Considering the work-related health problems that led to absence and were reported by 31 participants, fatigue accounted for $16.6 \%$, burnout $9.7 \%$, and labyrinthitis $9.7 \%$. For those who have been absent due to work-related health problems, one day was the minimum and 60 days the maximum (mean 19 days). The relationship between work accidents and seeking an occupational physician was also questioned (Table IV).

The risks to which anesthesiologists are exposed are numerous and some of them were asked to be qualified by the professional regarding damage (Table V). Work may be an impairment for relationships, so anesthesiologists were asked about this possible damage. For $38 \%$ of participants, working as an anesthesiologist moderately affects their relationships outside the workplace, $37.6 \%$ reported that it affects a little, and $12.7 \%$ stated that it greatly affects their relationships outside the workplace.

The relationship with colleagues was also questioned. Of participants, $58 \%$ consider their relationship with colleagues "good", 21.7\% consider it "very good", 12.1\% consider it "median", and only $5.7 \%$ consider it "very bad". Four subjects $(2.5 \%)$ did not answer this question and no one rated the relationship as "bad."

Alcohol consumption in this population had a positivity rate to 104 of respondents (67\%) and of these, 16 were considered CAGE positive (two or more positive responses). Because of the sensations that the anesthetics and other drugs can trigger, its use for relaxing or recreational purposes was suggested and 20 respondents (12.7\%) reported having used some of these drugs for this purpose (Table VI).

The association between CAGE and work overload could be demonstrated using the chi-square test. Those who feel overloaded or too overloaded tend to have very positive score on CAGE (Table VII).

Table III - Distribution of Anesthesiologists from Belo Horizonte According to Various Health Problems Resulting in Absence from Work, Anesthesiology as a Cause of Illness Affecting Co-workers, and Work that Triggers Health Problem, year 2010

\begin{tabular}{|c|c|c|c|c|c|c|c|c|}
\hline Variables & Yes & & No & & & med & Tota & \\
\hline & $\mathrm{N}$ & $\%$ & $\mathrm{~N}$ & $\%$ & $\mathrm{~N}$ & $\%$ & $\mathrm{~N}$ & $\%$ \\
\hline Health problems resulting in absence from work & 31 & 20 & 122 & 78 & 4 & 3 & 157 & 100 \\
\hline Practice of anesthesiology caused illness in a co-worker & 122 & 78 & 31 & 20 & 4 & 3 & 157 & 100 \\
\hline Work triggered health problems & 77 & 49 & 78 & 50 & 2 & 1 & 157 & 100 \\
\hline
\end{tabular}

Table IV - Distribution of Anesthesiologists from Belo Horizonte According to Number of Occupational Accidents and Visiting the Occupational Health Doctors, year 2010

\begin{tabular}{lllll}
\hline $\begin{array}{l}\text { Have experienced any occupational } \\
\text { accident }\end{array}$ & If, in case of accident, visited the occupational physician & Total \\
\hline Yes & 44 & 44 & 64 & 88 \\
No & & 1 & 4 & 65 \\
Not informed & 44 & 45 & 68 & 4 \\
Total & 44 & 157 \\
\hline
\end{tabular}


Table V - Classification of Anesthesiology Related Risks by Anesthesiologists from Belo Horizonte, year 2010

\begin{tabular}{|c|c|c|c|c|c|c|c|c|c|c|c|c|c|}
\hline \multicolumn{14}{|l|}{ Risk Classification } \\
\hline \multirow{2}{*}{ Risks } & \multicolumn{2}{|l|}{ VH } & \multicolumn{2}{|l|}{$\mathrm{H}$} & \multicolumn{2}{|l|}{$\mathrm{MH}$} & \multicolumn{2}{|l|}{ LH } & \multicolumn{2}{|l|}{$\mathrm{NH}$} & \multicolumn{2}{|l|}{$\mathrm{NI}$} & \multirow[t]{2}{*}{ Total } \\
\hline & $\mathbf{N}$ & $\%$ & $\mathbf{N}$ & $\%$ & $\mathbf{N}$ & $\%$ & $\mathbf{N}$ & $\%$ & $\mathbf{N}$ & $\%$ & $\mathbf{N}$ & $\%$ & \\
\hline Anesthetic gases & 24 & $15 \%$ & 45 & $29 \%$ & 50 & $32 \%$ & 21 & $13 \%$ & 13 & $8 \%$ & 4 & $3 \%$ & 157 \\
\hline Latex & 16 & $10 \%$ & 44 & $28 \%$ & 41 & $26 \%$ & 32 & $20 \%$ & 18 & $11 \%$ & 6 & $4 \%$ & 157 \\
\hline Addition & 41 & $26 \%$ & 26 & $17 \%$ & 40 & $25 \%$ & 22 & $14 \%$ & 9 & $6 \%$ & 19 & $12 \%$ & 157 \\
\hline Ionizing radiation & 73 & $46 \%$ & 43 & $27 \%$ & 26 & $17 \%$ & 8 & $5 \%$ & 0 & $0 \%$ & 7 & $4 \%$ & 157 \\
\hline Blood and secretions & 79 & $50 \%$ & 47 & $30 \%$ & 25 & $16 \%$ & 2 & $1 \%$ & 0 & $0 \%$ & 4 & $3 \%$ & 157 \\
\hline Work overload & 82 & $52 \%$ & 48 & $31 \%$ & 21 & $13 \%$ & 2 & $1 \%$ & 0 & $0 \%$ & 4 & $3 \%$ & 157 \\
\hline Explosions and fires & 25 & $16 \%$ & 26 & $17 \%$ & 30 & $19 \%$ & 41 & $26 \%$ & 29 & $18 \%$ & 6 & $4 \%$ & 157 \\
\hline Electricity & 20 & $13 \%$ & 27 & $17 \%$ & 33 & $21 \%$ & 51 & $32 \%$ & 22 & $14 \%$ & 4 & $3 \%$ & 157 \\
\hline Piercing/Cutting material & 99 & $63 \%$ & 39 & $25 \%$ & 12 & $8 \%$ & 3 & $2 \%$ & 0 & $0 \%$ & 4 & $3 \%$ & 157 \\
\hline Noise & 28 & $18 \%$ & 52 & $33 \%$ & 41 & $26 \%$ & 24 & $15 \%$ & 8 & $5 \%$ & 4 & $3 \%$ & 157 \\
\hline Other risk factors & 3 & $38 \%$ & 1 & $13 \%$ & 0 & $0 \%$ & 0 & $0 \%$ & 0 & $0 \%$ & 4 & $50 \%$ & 8 \\
\hline
\end{tabular}

VH: Very harmful; H: harmful; MH: moderately harmful; LH: little harm; $\mathrm{NH}$ : no harm; NI: not informed.

Table VI - Frequency of the Use of Substances Listed by Anesthesiologists from Belo Horizonte, year 2010

\begin{tabular}{|c|c|c|c|c|c|c|c|}
\hline Substance & \multicolumn{6}{|c|}{ Use of any substance } & \multirow{2}{*}{ Total } \\
\hline & $\mathrm{N}$ & $\%$ & $\mathrm{~N}$ & $\%$ & $\mathrm{~N}$ & $\%$ & \\
\hline Amphetamines & 3 & 2 & 148 & 94 & 6 & 4 & 157 \\
\hline Inhalation anesthetics & 2 & 1 & 149 & 95 & 6 & 4 & 157 \\
\hline Anxiolytics & 42 & 27 & 110 & 70 & 6 & 4 & 158 \\
\hline Marijuana & 5 & 3 & 146 & 93 & 6 & 4 & 157 \\
\hline Cocaine /Crack & 0 & 0 & 151 & 96 & 6 & 4 & 157 \\
\hline Other substances & 2 & 1 & 151 & 96 & 4 & 3 & 157 \\
\hline
\end{tabular}

Table VII - Frequency of the Level of Workload Related to CAGE and SRQ-20 in Anesthesiologists from Belo Horizonte, year 2010

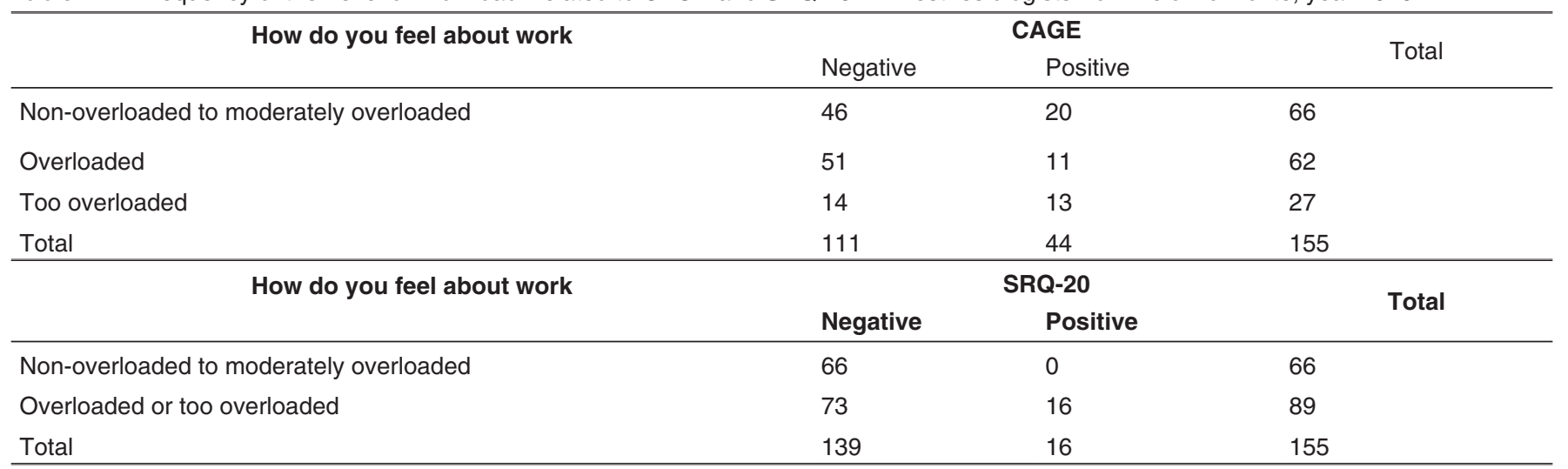


In the analysis of CMD using SRQ-20 and considering the criterion of positivity as seven affirmative questions for both sexes, 23 women and 21 men were classified as SRQ-20 positive. To assess the association between two variables (overload at work and SRQ-20), we also used Pearson's chi-square test that showed an association between how the individual feels about the work and SRQ-20 score, with the highest frequency of $S R Q-20$ positive among those who feel too overloaded (Table VII).

\section{DISCUSSION}

The random selection of the population to participate in the study was done actively, which is not suitable for comparison with the literature on adherence to research performed by sending questionnaires.

The number of male participants was higher in this study, unlike the study conducted in other Brazilian state ${ }^{12}$. However, there was similarity regarding predominance of married anesthesiologists with TEA as the highest degree, followed by $\mathrm{TSA}^{12}$. It was not possible to assess the prevalence of specializations, such as Intensive Care and Pain Clinic, as they may not have been considered by the professional as their highest level of education and, consequently, were not mentioned. In addition, there are professionals without the specializations considered engaged in these activities, which could be contradictory when portrayed the percentage of weekly time devoted to each work activity. Nevertheless, the fact that a large number of anesthesiologists evaluated devotes most of their time to the practice of Anesthesiology was seen.

Considering the medical work in general ${ }^{13}$ and in particular the anesthesiologist 14,15 , the working conditions associated with the current pay has led these professionals to exhaustive schemes of shifts exceeding 24 hours uninterrupted, i.e., no respite, which is advocated by the Federal Council of Medicine after shifts. In this sense, no reason for pride, this study corroborates the current situation of the Brazilian medicine.

Of 155 anesthesiologists, 145 reported working in shifts, accounting for $91.1 \%$. Most have day and night work schedules, and one participant reported having worked 22 night shifts of 12 hours in the previous month. Considering a month's work, this professional spent $73.3 \%$ of his nights working. The same participant reported having no time to rest after duty. Sleep deprivation is an important feature and extremely relevant to be considered, not to mention burnout and its disastrous consequences both for professionals and their patients ${ }^{14,16}$. Most of these physicians reported that at least one of their shifts happen in urgent and emergency services, which can be considered as another risk factor for illness, as control over the work, a very important factor in job satisfaction, especially in these cases, is nonexistent, and any type of patient may require assistance at any time ${ }^{17,18}$.

Working at hospitals is a reality in anesthesiology, although the service of anesthesiology at outpatient clinics and office presents strong growth trends. Regarding employment, as an important epidemiological characterization because it is directly related to payment, anesthesiologists have followed a trend of the current medical market: to work independently or becoming a partner with anesthesiology companies ${ }^{19}$. Also following this trend, the private sector through health insurance was the most reported as the universe served ${ }^{8}$.

Surgical complexity and type of patient under anesthesia can be considered as a stress factor for this professional, as complications are expected in more complex procedures and more critically ill patients, although this correlation was not questioned here. Moreover, time restrictions and work interference in everyday life are factors already studied and seen as strongly associated with damage ${ }^{20}$. In this study, however, the relationships with co-workers and outside the workplace seem not to interfere or appear to have little influence on the work, which goes against previous studies ${ }^{20}$.

Analyzing working conditions and risk perception, the anesthesiologists surveyed see hospitals, their main place of work, as a supplier of suitable conditions. If we consider that organizational factors are depicted as working conditions, this would be regarded as an important causative agent of stress here shown as controlled and, therefore, a possible generator of satisfaction 20 .

The anesthesiologist is classified here as an overworked and tired professional. The routine work does not allow time to rest during their journey. Time interval for meals is reported as insufficient and even nonexistent for some. Nevertheless, the vast majority rated themselves as satisfied with their medical specialty and they would not have chosen another profession or medical specialty. This could be justified by the satisfaction reported with the organizational factors ${ }^{20}$, the fact that everyday tasks are considered as varying over the day of the week, in addition to observing the poor working conditions and payment of most Brazilian physicians from different specialties $8,19,21$.

Despite the satisfaction, they recognize the work overload and this occupational risk and "blood and secretions" are classified as the most important risk factors, receiving the worst score in terms of damage by most professionals ${ }^{22,23}$.

It is noteworthy that half of anesthesiologists perceive work as a trigger of illness at some stage of their working life and the other half consider it as a cause for the illness of colleagues.

In case of work accidents, very common among health professionals, especially with piercing/cutting instruments, only $60 \%$ of anesthesiologists surveyed reported having experienced some type of accident at work, with $30 \%$ seeking medical care, according to legislation ${ }^{24}$.

Alcoholism, often observed in the medical field, was investigated in this study using the CAGE, and $15 \%$ of respondents were considered CAGE positive. This percentage was slightly lower than that showed by a study among doctors from Salvador ${ }^{8}$. In the general population, a study in Sao Paulo showed prevalence of CAGE positive in $7.8 \%$ of respondents ${ }^{25}$. It was found that all participants with CAGE positive feel overwhelmed at work, which may show alcohol consumption as a reaction to stress at work ${ }^{20}$. The relationship between alcohol and work overload was seen in $30 \%$ of anesthesiologists surveyed. 
Alcohol and drugs such as marijuana may serve as a trigger for abuse of other substances, such as opioids and inhaled anesthetics. Among the medications used at work and consumed by the professional, the most commonly used were anxiolytics. Of major concern to the field, the powerfully addictive drugs such as opioids were mentioned, as well as inhaled anesthetics ${ }^{26,27}$.

The prevalence of SQR-20 positive was $28.4 \%$, a value much higher than those found in studies of physicians and other professionals ${ }^{8,9,10}$. When SQR-20 was related to work overload, this association was statistically positive, indicating an expected result, as work overload is shown as a major generator of illness ${ }^{20}$.
The universe studied shows the anesthesiologist in the city of Belo Horizonte as a professional rather overloaded. Anesthesiology follows a global trend in the labor market in which precarious employment creates an increasingly competitive and unrestrained struggle for recognition and remuneration. To this trend, the risks inherent to the practice of this specialty are aggregated. The professional relationship with the work and the feelings resulting from it are subjective. Therefore, it becomes quite difficult for the anesthesiologist to know when to ask for help. Special attention should be given to these professionals, so that solutions can be sought and damage minimized or avoided. 


\section{REFERENCES}

1. Laurell AC, Noriega M - Processo de produção e saúde: trabalho e desgaste operário. São Paulo: Hucitec, 1989.

2. Mendes R, Dias EC - Da medicina do trabalho à saúde dos trabalhadores. Rev Saúde Pública, 1991;25 (5):341-349

3. Oddone I (org) - Ambiente de trabalho: a luta dos trabalhadores pela saúde. São Paulo: Hucitec, 1986.

4. Marconi MA, Lakatos EM - Metodologia científica. São Paulo: Editora Atlas SA, 2007, 5a ed..

5. Masur J, Monteiro M - Validation of the CAGE alcoholism screening test in Brazilian Psychiatry Inpatient Hospital Setting. J Biol Res, 1983;16:215-218.

6. Harding TW, Arango MV, Baltazar $\mathrm{J}$ et al. - Mental disorders in primary health care: a study of their frequency and diagnosis in four development countries. Psychol Med, 1980;10:231-241.

7. Mari J, Williams $P-A$ validity study of a psychiatry screening questionnaire (SRQ-20) in primary care in the city of São Paulo. Br J Psychiatry, 1986;148:23-26.

8. Sobrinho CLN, Carvalho FM, Bonfim TAS, Cirino CAS, Ferreira IS - Condições de trabalho e saúde mental dos médicos de Salvador, Bahia, Brasil. Cad Saúde Pública, 2006;22(1):131-140.

9. Borges LH, Faria MAM - Transtornos mentais menores entre trabaIhadores de uma usina siderúrgica. Rev Bras Saúde Ocupacional, 1993;21:7-18.

10. Faria NMX, Facchini LA, Fassa AG, Tomasi E - Processo de produção rural e saúde na Serra Gaúcha. Rev Saúde Pública, 1999;33:391 400.

11. Bolfarine H, Bussab WO - Elementos de amostragem. São Paulo: Editora Blucher, 2005.

12. Calumbi RA, Amorim JA, Maciel CMC, Filho OD, Teles AJF - Avaliação da qualidade de vida dos anestesiologistas da cidade do Recife. Rev Bras Anestesiol, 2010;60(1):42-51.

13. Barbosa GA - A saúde dos médicos no Brasil. Brasília: Conselho Federal de Medicina, 2007, pp. 220.

14. Howard SK, Rosekind MR, Katz JD et al. - Fatigue in anesthesia: implications and strategies for patient and provides safety. Anesthesiology, 2002;97:1281-1294.

15. Howard ASK - The anesthesiologist and fatigue. Am Soc Anesth Newsletter, 2001;65:1-4.

16. Calabrese G - Impacto de los calendarios laborales del anestesiólogo en la salud, el rendimiento y la seguridad. Rev Arg Anest, 2004;62(5):356-363.

17. Kinzl JF, Knotzer $\mathrm{H}$, Traweger $\mathrm{C}$ et al. - A influence of working conditions on job satisfaction in anaesthetists. Br J Anaesth, 2005;94(2):21115.

18. Araújo TM, Graça CC, Araújo E - Estresse ocupacional e saúde: contribuições do modelo demanda-controle. Cien Saúde Colet 2003;8(4):991-1003.

19. Conselho Regional de Medicina do Estado de São Paulo (Cremesp) - Mercado de trabalho médico no Estado de São Paulo. São Paulo: Cremesp, 2002. 
20. Kluger MT, Townend K, Laidlaw T - Job satisfaction, stress and burnout in Australian specialist anaesthetists. Anaesthesia, 2003;58:339345.

21. Goulart FAA (org) - Os médicos e a saúde no Brasil. Brasília: ConseIho Federal de Medicina, 1998, pp. 200.

22. Nyssen AS, Hansez I, Baele P, Lamy M, De-Keyser V - Occupational stress and burnout in anaesthesia. Br J Anaesth, 2003;90:333337.

23. Greene ES, Berry AJ, Arnold III WP et al. - Percutaneous injuries in anesthesia personnel. Anesth Analg, 1996;83:273-278.

24. Mérat $F$, Mérat $S$ - Risques professionnels liés à la pratique de l'anesthésie.Ann Fran Anesth Réanim, 2008;27(1):63-73.

25. Rego RA, Oliveira ZMA, Berardo FAN, Oliveira MB, Ramos LR - Epidemiologia do alcoolismo: prevalência de positividade do teste CAGE em inquérito domiciliar no município de São Paulo. Rev ABP-APAL, 1991;13(2):75-80.

26. Farley WJ, Talbott GD - Anesthesiology and addiction. Anesth Analg, 1983;62:465-466.

27. Farley WJ - Addiction and the anaesthesia resident. Can J Anaesth, 1992;39:R11-R17. 